\title{
MELANOMA EM CÃO COM MÚLTIPLAS METÁSTASES- RELATO DE CASO
}

Alessandra Castro Rodrigues ${ }^{1}$, Mariana Ribeiro de Castro¹, Erica Almeida Viscone1, Lígia Assunção Oliveira1 ${ }^{1}$, Alessandra Aparecida Medeiros ${ }^{2}$.

1- Médica veterinária residente em Patologia Animal, Universidade Federal de Uberlândia, Uberlândia - MG. E-mail: alessandracastroveterinaria@gmail.com 2- Professora doutora em Patologia Animal, Universidade Federal de Uberlândia, Uberlândia - MG.

\section{Recebido em: 08/04/2017 - Aprovado em: 10/06/2017 - Publicado em: 20/06/2017} DOI: 10.18677/EnciBio 2017A72

\section{RESUMO}

O melanoma é considerado neoplasia de células redondas, de origem em melanócitos e melanoblastos. É comumente encontrada em mucosa oral e globo ocular, sendo também comum metástases para linfonodos e pulmões. Este trabalho teve por objetivo relatar um caso de melanoma em cão com ocorrência de metástase em locais incomuns. Uma cadela, treze anos de idade, da raça Poodle foi encaminhada para avaliação clínica com nódulo cutâneo na altura do osso radio esquerdo. Após exame citológico diagnosticou-se melanoma e durante a necropsia observou-se metástases em vários tecidos como fígado, coração e sistema nervoso central. No exame microscópico notou-se proliferação de células redondas a alongadas, pouco diferenciadas, arranjadas em manto por vezes em feixes. As células neoplásicas apresentavam citoplasma escasso, e eosinofílico, com raras granulações de coloração marrom. O melanoma é uma neoplasia que pode apresentar metástases em locais incomuns, como fígado, coração e sistema nervoso central, além de linfonodos e pulmões, locais mais frequentemente relatados.

PALAVRAS- CHAVE: canino, metástase, neoplasia

\section{MELANOMA WITH MULTIPLE METASTASIS IN DOG - CASE REPORT}

\begin{abstract}
Melanoma is considered a neoplasia of round cells, originating in melanocytes and melanoblasts. It is commonly found in the oral mucosa and eyeball, and also metastases to lymph nodes and lungs. This work aimed to report a case of melanoma in dogs with metastasis in unusual places. A 13-year-old Poodle dog was referred for clinical evaluation with a cutaneous nodule at the height of the left bone. After cytologic examination, melanoma was diagnosed and necropsy revealed metastases in various tissues such as liver, heart and central nervous system. Microscopic examination revealed proliferation of elongated, slightly differentiated round cells, arranged in mantle, sometimes in bundles. Neoplastic cells had scarce cytoplasm, and eosinophilic, with rare granulations of brown color. Melanoma is a neoplasm that can present metastases in unusual places, such as the liver, heart and central nervous system, as well as lymph nodes and lungs, most frequently reported sites.
\end{abstract}

KEYWORDS: canine; metastasis; neoplasia. 


\section{INTRODUÇÃO}

Os melanomas são neoplasias com origem nos melanócitos e melanoblastos, células responsáveis por produzirem o pigmento melanina e que possuem origem embrionária no neuroectoderma (GOLDSCHMIDT \& GOLDSCHMIDT, 2017). Na epiderme, os queratinócitos que os circundam atuam regulando o comportamento e proliferação das mesmas. Assim, sua proliferação anormal é decorrente de alterações em moléculas de adesão e junções gap entre os melanócitos e queratinócitos, mais especificamente da E-caderina e conexina 43 respectivamente. (HAASS, et al., 2004; JIANGLAN et al., 2014).

São frequentemente relatados em cães e mais raramente em outras espécies como gatos, cavalos e animais selvagens terrestres e marinhos (NISHIYA et al., 2016). Os humanos também são acometidos e, neste sentido, os modelos animais são muitas vezes utilizados, principalmente em testes de novos tratamentos para o melanoma, visto que no homem esta neoplasia apresenta caráter agressivo, além de ser um dos mais freqüentes tumores de pele (STARKEY et al., 2005; JIANGLAN et al., 2014).

Não há predisposição racial para ocorrência de melanoma, porém raças como Schnauzer, Chow chow, Sharpei, Terriers, Pinscher e Doberman tem sido relatadas como mais frequentemente acometidas, sendo este fato associado à predisposição genética (GOLDSCHMIDT \& GOLDSCHMIDT, 2017). Com relação à idade, cães entre 9 e 13 anos são mais acometidos e não há predileção sexual (MODIANO et al.,1999; GOLDSCHMIDT \& GOLDSCHMIDT, 2017).

Grande parte dos melanomas ocorre em cavidade oral e junção mucocutânea dos lábios e apenas $10 \%$ destas neoplasias se originam na pele (GOLDSCHMIDT \& GOLDSCHMIDT, 2017). Na rotina clínica o melanoma pode surgir com inúmeras apresentações, podendo muitas vezes ser confundido com outros tumores de pele (GILLARD et al., 2013). Apesar de ser um tumor derivado de células pigmentadas, durante a diferenciação neoplásica, os melanócitos podem perder essa característica fazendo com que o tumor se apresente como nódulos pigmentados ou não (GOLDSCHMIDT \& GOLDSCHMIDT, 2017).

No estabelecimento do diagnóstico desta neoplasia deve-se considerar características macroscópicas e microscópicas, sendo a coleta de amostra para exame histológico essencial para avaliação do grau de malignidade, classificação do tumor e determinação do diagnóstico definitivo (MANZAN et al., 2005; GOLDSCHMIDT \& GOLDSCHMIDT, 2017).

Dependendo do grau de indiferenciação, este tumor pode ser extremamente semelhante a outras neoplasias como sarcomas, linfomas e tumores osteogênicos. Nestes casos, é necessário o uso de técnicas imunohistoquímicas para determinação do tipo de tumor. Na avaliação imunohistoquímica a proteína S-100 é frequentemente utilizada, sendo esta encontrada em células originadas da crista neural (GIUDICE et al., 2010). O uso de outros marcadores como c-kit, melan-A, e tirosinase também pode ser útil no estabelecimento do diagnóstico definitivo. (MODIANO et al., 1999; NEWMAN et al., 2012).

Os melanomas malignos, principalmente aqueles localizados em cavidade oral e globo ocular, facilmente sofrem metástases para linfonodos e pulmão, além de exibirem caráter infiltrativo, exigindo uma retirada cirúrgica com grande margem de segurança (MODIANO et al., 1999; GOLDSCHMIDT \& GOLDSCHMIDT, 2017).

A excisão cirúrgica é o tratamento de eleição e recomenda-se a exérese dos linfonodos próximos à neoplasia para avaliação de metástase. Este tratamento depende do estado geral do animal, visto que os benefícios da cirurgia podem ser 
menores, e assim diminuir a sobrevida do mesmo (LINDOSO et al., 2017). Outros tratamentos como radioterapia, quimioterapia e imunoterapia têm sido usados como terapia adjuvante. A sobrevida dos animais depois da retirada cirúrgica pode variar de quatro meses a um ano, dependendo do tamanho da neoplasia. Além disso, melanomas orais mostram um caráter mais agressivo, tendo o cão uma sobrevida média de três meses depois da retirada cirúrgica (MANZAN et al., 2005; NISHIYA et al., 2016).

Objetivou-se relatar um caso de melanoma em cão, sendo um caso incomum com metástase cerebral, hepática e em miocárdio, e assim gerar informações que auxiliem na identificação precisa desta patologia.

\section{RELATO DE CASO}

Uma cadela, treze anos de idade, da raça Poodle foi encaminhada ao Hospital Veterinário da Universidade Federal de Uberlândia com queixa de lesão na pele há aproximadamente quatro meses. Na avaliação clínica do animal identificouse massa cutânea localizada no membro anterior esquerdo, na altura do osso radio, medindo aproximadamente cinco centímetros de diâmetro, aderido à musculatura, ulcerado, de superfície irregular, coloração enegrecida e consistência macia. Coletou-se amostra por punção aspirativa com agulha fina (PAAF) da lesão para exame citológico, sendo o esfregaço corado com coloração Panótico Rápido $\left(\right.$ Renylab $\left.^{\circledR}\right)$. Foram identificadas células redondas bem delimitadas, com citoplasma moderado, levemente basofílico, com quantidade moderada de grânulos cor marrom. O núcleo apresentava-se redondo, fortemente basofilico, de localização central, cromatina frouxa, nucléolo evidente. Havia elevada anisocariose e moderada anisocitose, moderado pleomorfismo celular e em média uma figura de mitose por campo de grande aumento. As características celulares foram compatíveis com 0 diagnóstico de melanoma cutâneo.

Além disso, foram realizados exames complementares (hemograma e bioquímica sérica), sendo detectada discreta leucocitose e na avalição ecodopplercardiográfica constatou-se endocardiose da valva mitral.

Recomendou-se exérese cirúrgica como tratamento para a lesão cutânea, juntamente com medicação anterior ao procedimento cirúrgico (amoxilina e clavulanato de potássio, $50 \mathrm{mg} / \mathrm{kg}$, BID, durante 10 dias e anti-inflamatório nãoesteroidal firocoxib, $57 \mathrm{mg} / \mathrm{kg}$, SID, durante 7 dias) para controle da infecção no tumor ulcerado, alívio da dor e inflamação.

Após 20 dias da primeira consulta, o animal apresentou piora do quadro clínico e sem expectativa de melhora. Considerando o severo quadro clínico optouse pela eutanásia do animal e, com autorização do proprietário, o mesmo foi encaminhado para realização do exame necroscópico, com registro fotográfico das alterações macroscópicas e coleta de fragmentos para avaliação por microscopia de luz.

\section{RESULTADOS E DISCUSSÃO}

No exame macroscópico observou-se presença de massa localizada no membro anterior esquerdo medindo aproximadamente $5,0 \mathrm{~cm}$ de diâmetro, aderida à pele, de formato amorfo e coloração enegrecida, anteriormente diagnosticada como melanoma no exame citológico. As características morfológicas das células neoplásicas observadas no exame citológico foram semelhantes àquelas relatadas por DENICOLA (2009) que descreve o melanoma como células com formato redondo a poligonal, núcleo com localização paracentral, arredondado a oval, cromatina grosseira e nucléolo evidente, por vezes múltiplos nucléolos e de formato 
irregular. As células neoplásicas apresentam citoplasma com quantidade variável de grânulos de melanina. Além disso, vale ressaltar a eficácia do exame citológico para diagnóstico de melanoma, visto que as células esfoliam em abundância e são de fácil caracterização morfológica.

Durante o exame necroscópico observou-se na região lateral esquerda do tórax, caudalmente à escapula, massa arredondada, medindo $7,0 \times 7,0 \times 1,5 \mathrm{~cm}$, de consistência macia e coloração enegrecida. Próximo a esta, os linfonodos axilar e subescapular esquerdo se encontravam acentuadamente aumentados, com superfície irregular e de coloração marrom escura (Figura 1, A).

$\mathrm{Na}$ abertura da cavidade torácica, os pulmões apresentavam-se com múltiplos nódulos elevados, por vezes adentrando o parênquima, de formato arredondado, coloração amarronzada e medindo no máximo $1,0 \mathrm{~cm}$ de diâmetro cada (Figura 1, B). $\mathrm{Na}$ avaliação do coração observou-se nódulo em miocárdio direito, medindo aproximadamente $0,5 \mathrm{~cm}$ de diâmetro, de formato arredondado e coloração enegrecida (Figura 2, A).
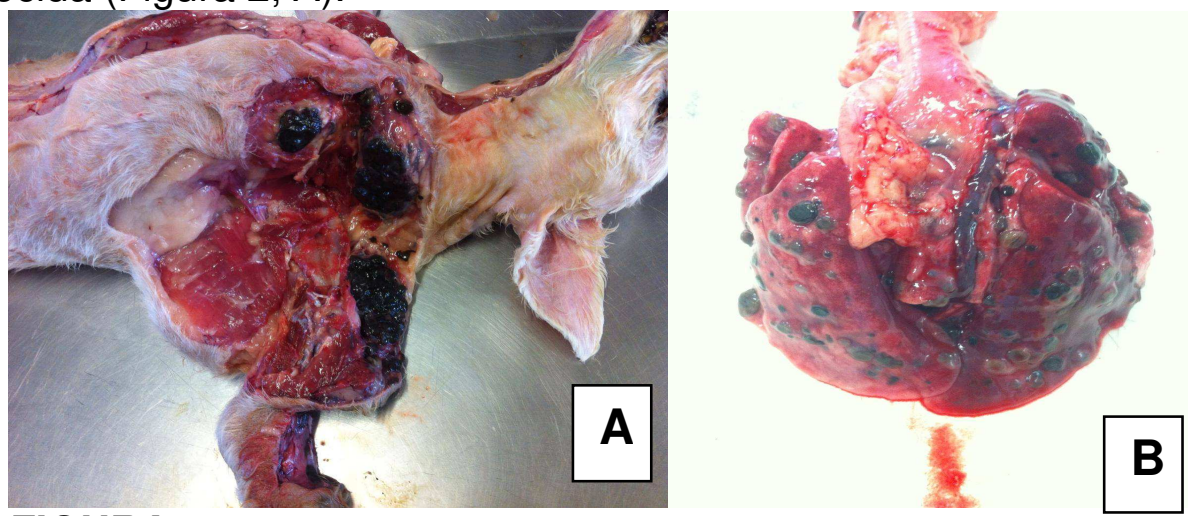

FIGURA 1. Cão, Poodle, 13 anos. (A) Massa enegrecida, localizada em região do linfonodo axilar e subescapular, (B) Nódulos enegrecidos com distribuição difusa no pulmão. Fonte: Arquivo pessoal.

O fígado encontrava-se aumentado de volume e com dois nódulos brancacentos, medindo aproximadamente $1,0 \mathrm{~cm}$ de diâmetro cada, de formato arredondado e que se aprofundavam ao corte. $\mathrm{Na}$ avaliação do sistema nervoso central, notou-se nódulo elevado sobre lobo temporal do hemisfério esquerdo, medindo aproximadamente $0,5 \mathrm{~cm}$ de diâmetro, de coloração enegrecida, que se aprofundava ao corte. (Figura 2, B).

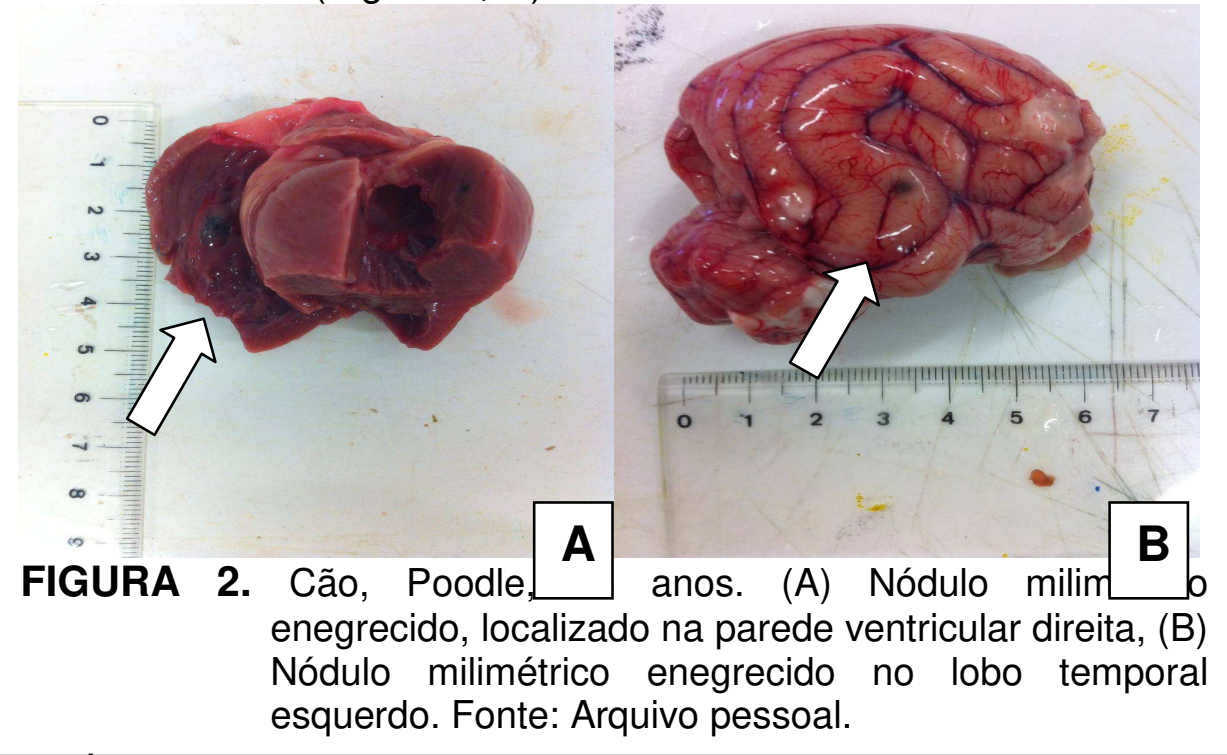


Foram coletados fragmentos dos órgãos com alterações e presença de massas enegrecidas, para análise histopatológica, fixados em formol $10 \%$ e processados de acordo com a rotina do laboratório de patologia animal da Universidade Federal de Uberlândia.

No exame microscópico notou-se proliferação de células redondas a alongadas, pouco diferenciadas, arranjadas em manto por vezes em feixes. As células neoplásicas apresentavam citoplasma escasso, e eosinofilico, com raras granulações de coloração marrom. Núcleos em formato arredondado a fusiformes, cromatina grosseira e nucléolo evidente. Exibindo moderada anisocitose e anisocariose com elevado pleomorfismo celular e em média três figuras de mitose por campo de grande aumento (Figura 3).
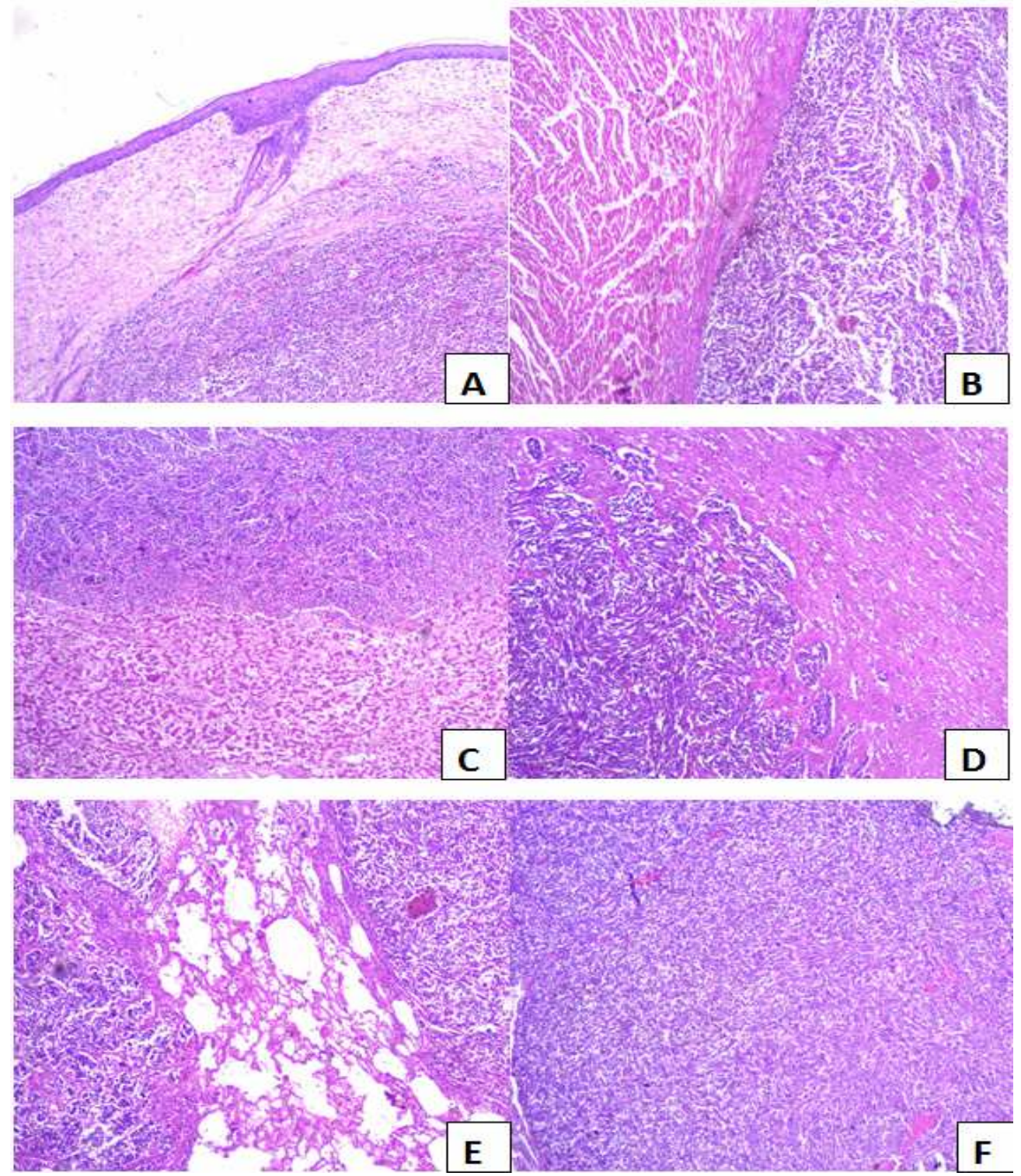

FIGURA 3. Cão, Poodle, 13 anos. Fotomicrografia de melanoma cutâneo $(A)$, metástase de melanoma no miocárdio (B), no fígado (C), no cérebro (D), no pulmão (E). Aumento de 10X. Melanoma cutâneo $(F)$, aumento $4 \mathrm{X}$. Fonte: Arquivo pessoal. 
As características histológicas foram compatíveis com o melanoma e anteriormente descritas por outros autores em localizações como globo ocular e cavidade oral e metástase em localidades como pulmão e linfonodos. (SIMPSON et al., 2013; GILLARD et al., 2014; NISHIYA et al., 2016; GOLDSCHMIDT \& GOLDSCHMIDT, 2017; LINDOSO et al., 2017). No presente trabalho relata-se a presença de metástase em locais incomuns como fígado, coração e sistema nervoso central (GOLDSCHMIDT \& GOLDSCHMIDT, 2017).

Quando possuem localização cutânea, os melanomas malignos têm crescimento rápido, geralmente pigmentados e ulcerados, compatível com o caso descrito nesse relato (NISHIYA et al., 2016). A idade de predileção para aparecimento de melanoma maligno em cão é no intervalo de 9 a 13 anos, o que condiz com o relatado no caso apresentado. O aparecimento da neoplasia na raça Poodle também já foi descrita em trabalhos anteriores, onde essa neoplasia pode se localizar tanto em pele quanto em mucosas orais e oculares (GILLARD et al., 2014; CORREA et al., 2016).

\section{CONCLUSÃO}

O melanoma é uma neoplasia que pode apresentar metástases em locais incomuns, como fígado, coração e sistema nervoso central, além de linfonodos e pulmões, locais mais frequentemente relatados. Sendo assim, ao ser diagnosticado melanoma em cães, deve-se atentar aos sinais clínicos que indiquem outros sítios de metástases, como por exemplo, sinais neurológicos, cardíacos e disfunções hepáticas.

\section{REFERÊNCIAS}

DENICOLA, D., Round Cells, In Cowell, R. L.; Tyler, R. D.; Meinkoth, J. H.; DeNicola, D. B. Diagnostic Cytology and Hematology of the Dog and Cat. 3 ${ }^{\underline{a}}$ ed. New York: Elsevier Inc. 2009.

GILLARD,M.; CADIEU E.; BRITO, C.; ABADIEj.; VERGIER B.; DEVAUCHELLE, P.; DEGORCE, F. E.; DREANO, S.; PRIMOT, A.; DORSO, L.; LAGADIC, M.; GALIBERT, F.; HEDAN, B.; GALIBERT, M. D.;\& ANDRE, C. Naturally occurring melanomas in dogs as models for non-UV pathways of human melanomas. Pigment cell \& melanoma research, v. 27, n. 1, p. 90-102, 2014. Disponível em: http://onlinelibrary.wiley.com/doi/10.1111/pcmr.12170/full DOI: 10.1111/pcmr.12170

GIUDICE, C., CECILIANI, F., RONDENA, M., STEFANELLO, D., \& GRIECO, V. Immunohistochemical investigation of PNL2 reactivity of canine melanocytic neoplasms and comparison with Melan A. Journal of veterinary diagnostic investigation, v. 22, n. 3, p. 389-394, 2010. Disponível em: http://journals.sagepub.com/doi/abs/10.1177/104063871002200307 DOI:

GOLDSCHMIDT, M. H., \& GOLDSCHMIDT, K.H. Epithelial and Melanocytic Tumors of the Skin. In Meuten, D. J., Tumors in Domestic Animals. 5 ${ }^{\underline{a}}$ ed. lowa: John Wiley \& Sons; 2017.

HAASS, N. K., SMALLEY, K. S., \& HERLYN, M. The role of altered cell-cell communication in melanoma progression. Journal of molecular histology, v. $35, \mathrm{n}$. 3, p. 309-318, 2004. Disponível em: 
LINDOSO, J. V. D. S., RUFINO, A. K. B., DA SILVA LUZ, P. M., DA SILVA, T. S., DE SOUSA JÚNIOR, F. L., DE SOUSA, F. B., \& DA SILVA SALES, K. D. K. Melanoma metastático em cão: Relato de caso. PUBVET, v. 11, p. 313-423, 2017. Disponível em: file:///C:/Users/residentehvet/Downloads/melanoma-metastaacutetico-emcatilde\%20(2).pdf DOI: 10.22256

LIU, J., FUKUNAGA-KALABIS, M., LI, L., \& HERLYN, M. Developmental pathways activated in melanocytes and melanoma. Archives of biochemistry and biophysics, v. $563, \quad$ p. 13-21, 2014. Disponível em: http://www.sciencedirect.com/science/article/pii/S0003986114002744 DOI: http://doi.org/10.1016/j.abb.2014.07.023

MANZAN, R. M., JUNIOR, A. R. S., PERINELLI, S. C., DE FÁTIMA BERTONCELLI, M., \& ZICA, V. P. Considerações sobre Melanoma Maligno em cães: uma abordagem histológica. Boletim de Medicina Veterinária, v. 1, n. 1, 2005. Disponível em: file://C:/Users/residentehvet/Downloads/BMV-2005-4\%20(4).pdf DOI:

MODIANO, J. F., RITT, M. G., \& WOJCIESZYN, J. The molecular basis of canine melanoma: pathogenesis and trends in diagnosis and therapy. Journal of veterinary internal medicine, v. $13, \quad$ n. $3, \quad$ p. 163-174, 1999. Disponível em: http://onlinelibrary.wiley.com/doi/10.1111/j.1939-1676.1999.tb02173.x/full DOI: 10.1111/j.1939-1676.1999.tb02173.x

NEWMAN, S. J., JANKOVSKY, J. M., ROHRBACH, B. W., \& LEBLANC, A. K. C-kit expression in canine mucosal melanomas. Veterinary pathology, v. 49, n. 5, p. 760765 , 2012. Disponível http://journals.sagepub.com/doi/abs/10.1177/0300985811414032 em: $10.1177 / 0300985811414032$

NISHIYA, A. T., MASSOCO, C. O., FELIZZOLA, C. R., PERLMANN, E., BATSCHINSKI, K., TEDARDI, M. V., GARCIA, J. S.; MENDONÇA, P. P.; TEIXEIRA, T. S.; \& ZAIDAN DAGLI, M. L. Comparative aspects of canine melanoma. Veterinary Sciences, v. 3, n. 1, p. 7, 2016. Disponível em: http://www.mdpi.com/2306-7381/3/1/7 DOI :10.3390/vetsci3010007

STARKEY, M. P., SCASE, T. J., MELLERSH, C. S., \& MURPHY, S. Dogs really are man's best friend-canine genomics has applications in veterinary and human medicine!. Briefings in functional genomics \& proteomics. v. 4, n. 2, p. 112-128, 2005. Disponível em: https://academic.oup.com/bfg/article/4/2/112/256454/Dogsreally-are-man-s-best-friend-Canine-genomics.

https://doi.org/10.1093/bfgp/4.2.112 